\title{
ESTUDIOS
}

\section{La enésima reforma de la Ley de Extranjería}

\section{Francisco García-Calabrés Cobo'}

Palabras clave: inmigrantes, ciudadanía, empadronamiento, reformas y retos.

Key words: immigrants, citizenship, registration, reforms and challenges.

Mots Clés: immigrants, citoyenneté, recensement, réformes et défis.

\section{Introducción}

El 26 de noviembre del año 2009, se produjo la aprobación definitiva por el Congreso de los Diputados de la última reforma de la Ley de Extranjería ${ }^{2}$, tras varias modificaciones sobre el texto original, y recibir 3 enmiendas a la totalidad y 731 enmiendas parciales. Dedicaremos las líneas de este estudio a profundizar en las aspectos más destacados que han motivado la cuarta reforma de la última Ley de Extranjería, las luces y sombras de su articulado, junto al calado y acierto de la misma, haciendo una especial consideración sobre la cuestión del empadronamiento y lo que podrían ser las bases de una futura regulación de este fenómeno en nuestro país.

1 Doctor en Derecho y Abogado. Profesor de Derecho Internacional Privado de la Universidad de Córdoba. Defensor de la Ciudadanía de Córdoba.

${ }^{2}$ Ley Orgánica 2/2009 de reforma de la Ley Orgánica 4/2000 de 11 de enero, sobre derechos y libertades de los extranjeros en España y su integración social. Publicada en el BOE de 11 de diciembre de 2009. 
Lo que realizaremos desde el punto de vista jurídico y normativo, pero también desde la óptica de los valores y los principios que han de regir la convivencia, como la igualdad jurídica, el respeto de las identidades, o el camino hacia una sociedad intercultural.

Y hablamos de enésima o penúltima reforma, porque pese a su gran calado, fue aprobada por un margen de 14 votos ante un Parlamento bipolarizado, lo que hace que siga siendo inexistente un pacto de Estado fundamental en esta materia. O dicho de otro modo, se convierte en una ley de partido, como la que vino a modificar.

\section{Justificación de la Reforma}

La última reforma de la Ley Orgánica 4/2000, más que tener un amplio calado, al modificar más de 60 de los 71 artículos del texto legal, la convierten en una nueva ley de extranjería tanto por la forma como por los contenidos; siendo el mayor cambio después de la modificación de 19 de diciembre de 2000, la Ley Orgánica $8 / 2000$, que supuso un nuevo rumbo introducido por la mayoría absoluta del partido político entonces gobernante, reforma que siete años después fue declarada parcialmente inconstitucional en numerosos de sus preceptos.

La justificación de la vigente reforma, la podemos agrupar en dos grandes líneas. De un lado procede a los obligados cambios técnico-jurídicos, tanto por la incorporación de la jurisprudencia del Tribunal Constitucional recogida en las sentencias 236/2007 de 7 de noviembre y 259/2007 de 19 de diciembre, así como por la transposición a nuestro ordenamiento jurídico de nueve directivas comunitarias. Así, la resolución de los recursos de inconstitucionalidad interpuestos contra la reforma que se introdujo en la Ley Orgánica de Extranjería la L.O 8/2000 suponen el reconocimiento de los derechos a todos los extranjeros con independencia de su situación documental de la asistencia jurídica gratuita en los procedimientos en que sean parte, así como del derecho de reunión, asociación, manifestación, sindicación y huelga, además de modificar las limitaciones en materia de educación no obligatoria.

De otro lado, también se ha procedido a la incorporación de la directivas comunitarias sobre la asistencia en casos de tránsito a efectos de repatriación o alejamiento 
por vía aérea ${ }^{3}$; sobre movilidad de residentes de larga duración en los países de la Unión Europea ${ }^{4}$; la expedición de permisos de residencia a nacionales de terceros países víctimas de la trata de seres humanos o hayan sido objeto de ayuda a la inmigración ilegal siempre que cooperen con las autoridades competentes ${ }^{5}$, - la obligación de los transportistas de comunicar los datos de las personas transportadas ${ }^{6}$; la referente a los requisitos de admisión de los nacionales de terceros países a efectos de estudios, intercambios de alumnos, prácticas no remuneradas o servicios de voluntariado 7 ; el procedimiento específico de admisión de los nacionales de terceros países a efectos de investigación científica ${ }^{8}$; la normativa sobre las normas y procedimientos en los Estados miembros para el retorno de los nacionales de terceros países en situación de estancia ilegal'; las condiciones de entrada y residencia de nacionales de terceros países para fines de empleo altamente cualificados ${ }^{10}$, y la relativa al establecimiento de normas mínimas sobre las sanciones y medidas aplicables a los empleadores de nacionales de terceros países en situación irregular ${ }^{11}$.

Todo ello sin olvidar la entrada en vigor en nuestro país de las obligaciones dimanantes del Convenio del Consejo de Europa sobre la lucha contra la trata de

${ }^{3}$ Directiva 2003/110/CE del Consejo, de 25 de noviembre de 2003 (DOUE de 6 de diciembre de 2003).

${ }^{4}$ Directiva 2003/109/CE del Consejo, de 25 de noviembre de 2003, relativa al Estatuto de los nacionales de terceros países residentes de larga duración (DOUE de 23 de enero de 2004).

${ }^{5}$ Directiva 2004/81/CE del Consejo, de 29 de abril de 2004 (DOUE de 6 de agosto de 2004).

${ }^{6}$ Directiva 2004/82/CE del Consejo, de 29 de abril de 2004 (DOUE de 6 de agosto de 2004).

7 Directiva 2004/114/CE de 13 de diciembre de 2004 del Consejo (DOUE de 23 de diciembre de 2004).

${ }^{8}$ Directiva 2005/71/CE de 12 de octubre de 2005 del Consejo (DOUE de 3 de noviembre de 2005).

${ }^{9}$ Directiva 2008/1 15/CEE de 16 de diciembre de 2008, del Parlamento Europeo y el Consejo (DOUE de 24 de diciembre de 2008).

${ }^{10}$ Directiva 2009/50/CE del Consejo, de 25 de mayo de 2009 (DOUE de 18 de junio de 2009).

11 Directiva 2009/52/CE del Parlamento Europeo y del Consejo de 18 de junio de 2009 (DOUE de 30 de junio de 2009). 
seres humanos ${ }^{12}$. Toda esta parte de la reforma era de obligado cumplimiento, tras sentencias judiciales y condenas internacionales a nuestro país. A pesar de todo ello, como acertadamente indica el informe de la Federación SOS Racismo ${ }^{13}$, la adaptación de la ley a la normativa europea es un proceso inacabado que seguramente obligará a nuevas modificaciones pues, por ejemplo, está pendiente de aprobación la propuesta de Directiva del Consejo de 23 de octubre de 2007, por la que se establece un procedimiento único de solicitud de un permiso que autoriza a los nacionales de terceros países a residir y trabajar en el territorio de un Estado miembro y por la que se establece un conjunto común de derechos para los trabajadores de terceros países que residen legalmente en un Estado miembro, - las propuestas legislativas en discusión aún sobre trabajadores temporeros, aprendices remunerados y personas dentro de una empresa.

La otra línea que completa la reforma, es de marcado carácter de política migratoria, como se recoge en el propio tenor literal de la Exposición de Motivos ${ }^{14}$, bajo el argumento de adaptación a la nueva realidad migratoria en España, con unas características y retos diferentes a los existentes nueve años atrás, y una presencia demográfica mucho mayor que representa el $12 \%$ de nuestra población. Frente a aquéllos 241.971 extranjeros residentes en España en el año $1985^{15}$, hoy nuestro padrón recoge a 5.600 .000 extranjeros, de los que más de 1.000 .000 tienen permiso de residencia permanente y casi 2.500 .000 son extranjeros comunitarios. También ha cambiado el contexto supranacional, y nuestra legislación ha de desarrollarse dentro de un nuevo marco europeo ${ }^{16}$ en el cual se establecen como principales objetivos conseguir una inmigración legal ordenada, la lucha contra la inmigración ilegal así como favorecer la integración de los inmigrantes legales mediante un equilibrio de derechos y deberes.

\footnotetext{
${ }^{12}$ Convenio n 197 del Consejo de Europa, hecho en Varsovia el 16 de mayo de 2005.

${ }^{13}$ Informe "Viejos remedios para nuevas realidades. Análisis de la Ley 2/2009 de reforma de la Ley de Extranjería", publicado por la Federación de Asociaciones SOS Racismo en el Estado Español, en enero de 2010.

${ }^{14}$ Apartado IV de la Exposición de Motivos de la Ley Orgánica, en el Boletín Oficial de las Cortes Generales de 7 de diciembre de 2009, núm. 31-14.

${ }^{15}$ Anuario de Migraciones, publicado por el Ministerio de Trabajo y Asuntos Sociales en 1996.

${ }^{16}$ Determinado por la firma del Pacto Europeo sobre Inmigración y Asilo, refrendado por el Consejo Europeo de 16 de octubre de 2008 por los 27 países miembros de la Unión Europea.
} 
Hay que hacer mención especial de que la reforma impulsada por el Gobierno de la Ley de Extranjería era necesaria a todas luces, pero se da en un contexto económico y político muy determinante, que condiciona en gran medida el avance legislativo de aquélla. En este sentido, uno de los grandes debates en torno al fenómeno migratorio, se centra en ponderar la influencia del mismo sobre nuestras economías ${ }^{17}$. En una economía de mercado como la nuestra, donde todo se mide en índices de rentabilidad y costes, de producción y beneficios, la resultante final del efecto del fenómeno migratorio es de máximo relieve, dado que la legislación y el ámbito de los derechos y, en definitiva, la modulación de la ciudadanía, desgraciadamente se atemperará al balance económico final. $\mathrm{O}$ dicho de otro modo, si con la llegada de inmigrantes hemos tenido altas tasas de crecimiento económico ello se corresponde con un relajado control de acceso a nuestras fronteras, regularizaciones de extranjeros indocumentados, reagrupaciones familiares y legislaciones proteccionistas de derechos humanos. Si por el contrario, como ahora, suben los índices del paro al 19\% y lejos del crecimiento nuestra economía se encuentra en recesión, la inmigración se traduce en amenaza, endurecemos la vigilancia fronteriza, nos planteamos los contratos de integración y los centros de "retención" administrativa de extranjeros de hasta 18 meses. Escribe Pedro Casaldáliga, que uno de los grandes males contemporáneos es la macroidolatría del mercado total. En ese contexto, se impone y desarrolla un discurso mercantilista sobre la inmigración, que se defiende en tanto resulta como fuerza de trabajo que mantiene sectores productivos que por su penosidad o precariedad los nativos no queremos ocupar, o como consumidores que alimentan el tirón del crecimiento interior, o como mantenedores de contribuciones al sistema financiero español, que ayuda al pago de las pensiones y que reparte la carga fiscal de los nacionales.

Esa visión utilitarista, se refleja también en el propio sistema de contratación, recogido en la normativa del contingente anual de trabajadores extranjeros. La misma se basa en que vengan el número de trabajadores extranjeros que nosotros queramos, de los países que nosotros decidamos, por el tiempo que digamos, para trabajar en las actividades y provincias que nos parezcan y... después que se vayan. Esta visión es la que aparece como tercera justificación formal de la reforma legal, según recoge la Exposición de Motivos de la Ley: la necesidad de adaptar la referida Ley Orgánica a la nueva realidad migratoria en España, que presenta unas características y plantea unos retos diferentes de los que existían cuando se aprobó la última reforma de la ley. Es cierto que hay menos trabajo, pero sigue existiendo el mismo derecho a ganarse un salario para mantenerse dignamente, $y$

17 García-Calabrés Cobo, F. (2009) Inmigrantes en España. Claves para comprender un fenómeno mundial, Editorial Laberinto, pp. 87-95. 
también es cierto que la convivencia exige parámetros de integración y de igualdad en el ejercicio de los derechos, que sin embargo esta ley no recoge.

$Y$ esto es determinante, porque en ese contexto se acomete la reforma de la ley por los mismos que han puesto en marcha a bombo y platillo un programa de retorno voluntario de extranjeros, que se anunció por el Ministro del ramo que llegaría directamente a 100.000 extranjeros que junto a sus familiares llevarían al retorno de un millón de personas, y que en el año 2009 afectó apenas a 15.000 solicitantes.

Son los mismos impulsores de la reforma quienes reconocieron su quebrantamiento de la ley de extranjería al facilitar la entrada en nuestro país sin pasaporte y por motivos políticos de Aminetu Haidar enviada por el Reino de Marruecos, en las mismas fechas en que el trámite parlamentario debate la reforma legal ${ }^{18}$.

Y a pesar de todo, de las contradicciones puestas anteriormente de manifiesto por los promotores de la reforma legal respecto de los objetivos que procuran, esta reforma resulta ahora mucho más amplia y equilibrada respecto a la formulada un mes antes por el principal partido de la oposición, de un calado menor y que incorporaba el contrato de integración como nueva herramienta, discutible y controvertida cuando menos, en el derecho de extranjería.

\section{Una triple ocasión perdida}

Lamentablemente para la sociedad española, la última reforma de la ley de extranjería resulta contradictoria, en línea con lo desarrollado estos últimos 25 años desde la primera Ley Orgánica de Extranjería 1/1985 de 7 de julio; coyunturalista pues no da una respuesta global a los retos y las necesidades que los extranjeros presentan en la sociedad española; y de partido, ajena a un gran consenso que

${ }^{18}$ Véase en el Boletín Oficial del Congreso de los Diputados del día 26 de noviembre de 2009, la intervención del Sr. Hernando Fraile, del Grupo Popular, en el debate de la reforma legal, en la sesión plenaria: "Esto es lo que ha hecho el Gobierno y el señor Moratinos; han permitido la entrada ilegal de una persona a la que las autoridades marroquíes habían incautado su pasaporte. Ha obligado a incumplir la Ley de Extranjería a propios y a extraños, a policías de frontera, a pilotos de aeronaves, a compañías aéreas que están sancionados en el artículo 56 de esta ley. Ha mentido sobre la documentación que el artículo 25 considera necesaria para entrar en nuestro país.... porque esta señora está aquí contra su voluntad, separada de sus hijos, de su familia y de su tierra, y resulta mezquino hablar en esos términos de esta persona. Por tanto, señores del Gobierno, cumplan con su obligación, cumplan las leyes -incluso las que aprueban ustedes- y promuevan que esta persona vuelva a su país, con los suyos, y acaben con una situación infame y vergonzosa para España y los españoles". 
ofrezca criterios y estabilidad de una vez a la legislación española en esta materia; además de cicatera con los derechos de los extranjeros, a pesar de verse obligada por el Tribunal Constitucional a enmendar las privaciones y restricciones mantenidas sobre los derechos de los extranjeros durante 7 años por gobiernos diversos.

España ha tenido tradicionalmente una política errática y contradictoria en materia de legislación de extranjería, fruto de una falta de debate en profundidad del fenómeno migratorio, de una política sectaria que ha obviado un gran consenso de Estado, además de una aproximación muy sesgada, utilitarista y mercantilista de esta realidad.

Ejemplos de esa política ayuna de criterios definidos y errática los encontramos en demasía. Así, hemos pasado de firmar convenios bilaterales de doble nacionalidad y reciprocidad con los países de vinculación histórica con España, a suprimir dichos criterios y exigirles visado de entrada. De facilitar hasta siete procesos de regularizaciones extraordinarias que han servido como el mayor cauce de obtención de la residencia legal en nuestro país, a organizar programas de retorno voluntario de extranjeros. De crear un contingente para trabajadores extranjeros que durante años sirvió de regularización encubierta a ser el instrumento de la contratación en origen, siendo luego exclusivo para la contratación de extranjeros y ahora totalmente restringido.

El sectarismo político ha sido otro de los caracteres que han acompañado al legislador español, pues las leyes aprobadas siempre lo fueron con la oposición del otro partido mayoritario. Incluso con la manifestación de enormes contradicciones internas en el seno de las propias fuerzas políticas. Baste recordar como el partido gobernante en el año 2000, antes y después de las elecciones generales, aprobó en el Parlamento dos leyes contrarias entre sí en materia de extranjería, la Ley Orgánica 4/2000 y la Ley Orgánica 8/2000. O como el actual partido gobernante, ha pedido en reiteradas ocasiones ${ }^{19}$ la ratificación del Convenio de Naciones Unidas sobre Trabajadores Migrantes y su Familiares, aprobado el 18 de diciembre de 1990 por la Resolución 45/158 de la Asamblea General, lo que luego no ha realizado tras 6 años de gobierno. No se pierda de vista que, al margen de los dictámenes preceptivos emitidos por el Consejo de Estado, el Consejo General del Poder Judicial o el Foro para la Integración Social de los Inmigrantes, la actual reforma legal es ajena a las peticiones y sugerencias de organismos y entidades muy implicados en esta realidad como la Red Acoge, el

${ }^{19}$ Entre ellas, la que se recoge en el Boletín Oficial del Congreso de los Diputados de 9 de diciembre de 2003, serie $D$, número 636, páginas 10-12. 
Consejo General de la Abogacía Española, Cáritas, CEAR o Amnistía Internacional, entre otros. En el terreno de lo político, la mayoría de las enmiendas que se aceptaron para conseguir la necesaria mayoría parlamentaria, fueron de CIU, el PNV que finalmente votaría en contra, y Coalición Canaria. La votación final del proyecto de ley no pudo ser más desalentadora para la sociedad española: 180 votos a favor (PSOE, CIU y Coalición Canaria) y 163 votos en contra (PP, IU-ICVERC y PNV). La carencia de consensos importantes lleva la vigencia de la Ley a la incertidumbre de los próximos resultados electorales, lo mismo que ocurrió hace 10 años con la ley de extranjería ahora reformada.

Las leyes de extranjería desde el año 1985 en nuestro país, han sido fundamentalmente leyes de control de fronteras, expedición de permisos y visados, y régimen sancionador; pero no han sido leyes de inclusión social ni determinación del estatuto de ciudadanía. Hay que tener en cuenta que, hasta 10 años después de la aprobación de aquélla primera ley, no se aprobó un plan de integración de los inmigrantes. O más recientemente, hay que traer a colación, como muestra de esta falta de esa sensibilidad, la sentencia del Tribunal Constitucional del año 2007 que anuló parte de la reforma de la ley de extranjería de diciembre del año 2000 por ser contraria a los derechos fundamentales de las personas protegidos en nuestro Ordenamiento Jurídico.

El propio Consejo Económico y Social en el año 2006, ante los disturbios generalizados protagonizados por inmigrantes en el país galo durante el otoño anterior, ya planteó la necesidad de dotarse de una estrategia de integración social de los inmigrantes, y abandonar una visión mercantilista y utilitarista de los mismos como mera mano de obra del sistema productivo, para satisfacer las necesidades de los trabajos intensivos y de más escasa cualificación que no resultan cubiertos por la mano de obra nacional de un lado, y como contribuyente a las arcas públicas, de otro.

Ante una legislación de tanto alcance social, que afecta de manera directa a los derechos y expectativas de los 5.600 .000 extranjeros que se encuentran empadronados en nuestro país, parece que lo más razonable no es desarrollar políticas de partido, donde quien gobierna crea su propia ley que deroga la del gobierno anterior. Desgraciadamente, no nos queda ninguna duda de que esto es justamente lo que se acaba de hacer nuevamente, como literalmente recoge el debate parlamentario ${ }^{20}$ en el que tanto el portavoz del Grupo Parlamentario Vasco como el del

${ }^{20}$ Véase Boletín Oficial del Congreso de los Diputados de 26 de noviembre de 2009, la intervención en la sesión plenaria del Sr. Olabarría Muñoz y del Sr. Hernando Fraile. 
Grupo Popular insisten en que es una ley manifiestamente insuficiente, que no dará respuesta a los problemas de los inmigrantes y de la sociedad española. Partidos políticos de todo el arco ideológico, tanto de derechas como de izquierdas, tanto nacionalistas como estatales, han desaprobado esta ley. Se ha repetido nuevamente el tradicional enfrentamiento de nuestra clase política en esta materia que tuvo un capítulo anterior en la campaña de las elecciones generales de marzo de 2008, donde se hizo bandera política sobre los derechos de las personas extranjeras que viven en nuestra comunidad, avivando en ocasiones el sentimiento xenófobo de la sociedad, basado en estereotipos y estigmas, como viene desgraciadamente ocurriendo, además, en países de nuestro entorno como Francia, donde el partido ultraderechista de Jean Mari Le Pen concurría a las elecciones bajo el lema de "Los franceses, primero".

$Y$ es que en esta materia, como en otras fundamentales, se impone desarrollar políticas de Estado, equilibradas, con visión de futuro, y que sean asumidas por la sociedad. Pacto de Estado ausente que requiere diálogo y consenso entre los tres niveles de gobierno y de administraciones públicas, ya que todos tienen competencias propias que inciden sobre esta realidad, que requiere no sólo de mayor coordinación, sino de convergencia sobre un modelo común. No es posible que en la Comunidad Valenciana se exija un contrato de integración a los inmigrantes ${ }^{21}$, que La Rioja se niegue a la acogida de menores extranjeros frente a la saturación de la Comunidad Canaria, o que algunos ayuntamientos nieguen o dificulten el empadronamiento en su municipio de los extranjeros sin tarjeta de residencia legal frente al mandato de la ley. Para ello, hubiese sido adecuada la mayor utilización, diálogo y consenso de los foros previstos en éste ámbito, como el Consejo Superior de Política de Inmigración convertido ahora en la Conferencia Sectorial de Inmigración ${ }^{22}$, la Comisión Laboral Tripartita, la Comisión Interministerial de Extranjería o el Foro para la Integración Social de los Inmigrantes.

Pero para ello, se exige previamente que exista una pedagogía social, que ahora tampoco se ha realizado, perdiéndose una ocasión que, aún mediatizada por la

${ }^{21}$ Ley 15/2008 de 5 de diciembre, de integración de las personas inmigrantes en la Comunitat Valenciana. BOE 10 de enero de 2009.

${ }^{22}$ Regulado en el artículo 68 de la LOEX, tiene como misión ser el órgano a través del cual se asegurará la adecuada coordinación de las actuaciones que desarrollen las Administraciones Públicas en materia de inmigración. Si bien la Ley no determina su composición, ni participación de las Administraciones Locales, aunque por el tenor literal del artículo 2 ter, se establece que el Gobierno y las Comunidades Autónomas acordarán programas de acción bienales para reforzar la integración social de los inmigrantes, con lo que parece que aquéllas están excluidas de dicho órgano. 
coyuntura económica, resultaba irrenunciable para una correcta apreciación del fenómeno migratorio y su consecuente regulación. Pedagogía social que explique a las claras, el balance positivo, económico y demográfico, de la inmigración en nuestro país, que elimine los miedos identitarios y culturales apuntando hacia una sociedad intercultural y pluriétnica.

Por eso decimos que la reforma de la Ley de Extranjería que analizamos supone una triple ocasión perdida: la de apostar por una legislación de extranjería inclusiva orientada a conseguir la equiparación de los extranjeros y el pleno disfrute de la ciudadanía; la ocasión de haber conseguido un amplio pacto de Estado entre las fuerzas políticas y el conjunto de administraciones públicas; y la posibilidad perdida de facilitar previamente un debate social reflexivo y de calado sobre este fenómeno.

La Subcomisión de Extranjería del Consejo General de la Abogacía al día siguiente de aprobarse la ley, se posicionó en dicho sentido ${ }^{23}$ al argumentar que el proceso de reforma hubiera debido servir de escenario de reflexión a todos los estamentos implicados en la regulación de la situación jurídica de los extranjeros en España, para desarrollar un Derecho de Extranjería, con vocación de permanencia y estabilidad -sea cual fuere el partido en el gobierno del Estado-. Con la persona como centro de su regulación y con la firme voluntad de reconocer y garantizar los Derechos Humanos de las personas migrantes. Así el Consejo General de la Abogacía Española augura un corto recorrido al texto aprobado ya que en su opinión, el reto actual de las políticas migratorias no es precisamente el control de las entradas o control de fronteras, de lo que se está encargando la coyuntura socioeconómica, sino que el verdadero desafío de las políticas migratorias está en la capacidad de las sociedades europeas para regular adecuadamente la llegada de personas y principalmente la convivencia entre personas de muy diferentes orígenes y procedencias geográficas y culturales que se encuentran ya presente en el territorio español y europeo, que en mucho casos permanecen desde años y han venido para quedarse.

Termina señalando el máximo órgano de los abogados españoles que lamentan que estemos ante una nueva ocasión fallida que, en su opinión, nos coloca ante el compromiso de trabajar por la elaboración de una norma que sea capaz de responder a la actual realidad migratoria y a los retos que todo ello comporta, especialmente en el ámbito de la integración.

${ }^{23}$ Véase nota de prensa publicada el 27 de noviembre de 2009, bajo el título "La LOEX ha experimentado mejoras pero sigue sin respetar derechos fundamentales de las personas" en www.cgae.es. 


\section{Aportaciones y novedades}

A pesar del carácter ambivalente de la norma, donde sobresalen algunos aspectos contradictorios, entramos ahora a reseñar aquellos más destacados que valoramos con carácter positivo.

El respeto al contenido de algunos derechos fundamentales como los de asociación, reunión y manifestación, sindicación y huelga, que resulta más ajustada al mandato y a la jurisprudencia del Tribunal Constitucional. Ya que en la reforma de la Ley de Extranjería 8/2000 se introdujo el requisito de que dichos derechos sólo fuesen ejercidos por extranjeros siempre que fuesen residentes legales en nuestro país. La doctrina del Alto Tribuna ${ }^{24}$ señaló que esos preceptos eran contrarios, entre otros, a los artículos 21 y 22 de la $C E$, recogiéndose ahora el carácter universal de tales derechos, sin sujeción a restricción alguna basada en la situación administrativa o documental del extranjero.

Un avance sustancial, aunque demasiado tardío, es preservar el derecho a la asistencia jurídica gratuita de todos los extranjeros con independencia de cual resulte su situación administrativa, pues ya desde la sentencia del Tribunal Constitucional 95/2003 el Alto Tribunal ha venido afirmando reiteradamente la inconstitucionalidad de la exigencia del requisito de la residencia para que los extranjeros puedan acceder a la asistencia jurídica gratuita en relación con cualquier tipo de proceso, siendo la asistencia jurídica gratuita un derecho instrumental a la tutela judicial efectiva, cuyo contenido constitucional es indisponible para el legislador. Sin embargo, pese a que se mejoró su redacción con las enmiendas del Senado, no se incluyeron expresamente los procedimientos de repatriación en el caso de menores como recogía el Dictamen del Foro por la Integración Social de los Inmigrantes. En cambio, en materia procesal, también ha supuesto un avance el reconocimiento de la capacidad de obrar de los menores no acompañados en los procedimientos de repatriación.

También el establecimiento de mecanismos de protección en las situaciones de violencia de género, ha supuesto otro considerable avance que se ha materializado en el nuevo artículo 31 bis, dado que para quien se encontrase en situación irregular se suspende el procedimiento sancionador y se dicta una orden de protección, pudiéndose conceder una autorización de residencia provisional, que podrá convertirse en definitiva si existe sentencia condenatoria. Aunque se ha criticado en el Dictamen del Foro la necesidad de haber obviado el requisito de los antecedentes

${ }^{24}$ Por todas, la sentencia del Tribunal Constitucional 236/2007, Fundamento Jurídico $6^{\circ}$. 
penales, o el cómputo de figurar la persona como rechazable en el espacio territorial comunitario. Esta inclusión nos parecía necesaria dada la sobrerrepresentación de mujeres extranjeras víctimas de violencia de género que las estadísticas oficiales denuncian cada año. De otro lado, también se refuerza la colaboración contra redes organizadas $y$, en especial, respecto de las víctimas de trata de personas a través del nuevo artículo 59 bis, que incorpora el Convenio del Consejo de Europa sobre la lucha contra la trata de seres humanos de 16 de mayo de 2005. Si bien, igualmente el precepto se queda corto respecto del plazo de reflexión de al menos 30 días que se otorga a la víctima en orden a su determinación sobre si formulara la correspondiente denuncia. El Dictamen al Anteproyecto de Ley del Foro para la Integración Social de los Inmigrantes, ya incidía de un lado en el adecuado establecimiento de los recursos que hagan efectivo este derecho, y de otro lado recomendaba que se ampliase a 90 días dicho periodo de reflexión, de acuerdo con el contenido del Informe del Grupo de expertos sobre Trata de Seres Humanos de la Comisión Europea de 2004 sumadas a los expertos de la OSCE. El aumento de dicho periodo se justifica no sólo por la necesidad de ofrecer a la víctima un tiempo para decidir si denuncia o no, sino también por la necesidad de otorgarle un periodo de recuperación física y psicológica que, de seguro, va más allá de los 30 días.

En estos dos supuestos, de violencia de género y víctimas de trata de personas, la previsión normativa parte de forma paralela, primero de la incoacción del expediente sancionador contra la mujer, que luego se somete a suspensión si concurren determinados requisitos interpretables. Por ello, en el trámite parlamentario se presentaron hasta 23 enmiendas para que se suprimiese esa "espada de Damocles" que es el expediente sancionador previo, que fueron rechazadas. Y como laguna, dentro del avance que ya supone la nueva regulación, está dentro del campo de las alternativas, ya que a estas mujeres extranjeras sin documentación se las excluye de la renta activa de inserción, ya que no pueden figurar como demandantes de empleo como recoge la Orden TAS/3698/2006, con lo que el proceso de integración cuenta con serias dificultades.

Es la primera vez que la materia relativa a la integración de los inmigrantes aparece regulada en una ley orgánica, pues hasta ahora la integración resultaba rehén de los planes estratégicos ${ }^{25}$. Ahora, con carácter muy genérico, la norma prevé legalmente el respeto a la diversidad de identidades, así como las acciones formativas destinadas al aprendizaje del castellano y las lenguas cooficiales y el

${ }^{25}$ Desde el primer Plan de Integración del año 1994 al actual Plan Estratégico de Ciudadanía e Integración - $\mathrm{PECl}$ - para el período 2007-2010. 
conocimiento de los valores constitucionales. No obstante, surge la inquietud de que lo que eufemísticamente la ley denomina "esfuerzo de integración" 26 , se utilice como un medidor discrecional por parte de la Administración, para condicionar el acceso a la obtención o renovación del permiso, lo que nos recuerda la propuesta del contrato de integración.

La eliminación del criterio legal de reciprocidad para el ejercicio del derecho al sufragio en las elecciones municipales, aunque persista el reenvío a lo dispuesto en el texto constitucional (recogido en, el artículo 13.2 CE), entendemos que supone un tímido avance en la buena dirección. La reforma del 27 de agosto de 1992, que modificó el citado artículo, hizo posible el sufragio activo y pasivo en las elecciones municipales tanto de los extranjeros comunitarios, como de los no comunitarios. Sin embargo, el ejercicio de ese derecho para los últimos, estaba condicionado al cumplimiento de una serie de requisitos entre los que se encuentran el de reciprocidad, la exigencia de un tratado, la reducción de su ejercicio a las elecciones locales y también la exigencia de residencia administrativa en nuestro país para ejercer la titularidad sobre el mismo.

La habilitación para trabajar a los familiares reagrupados, entre los que ahora se incluyen a los de análoga relación de afectividad en las mismas condiciones que los cónyuges, supone un doble avance: de un lado, si hasta ahora los familiares obtenían sólo la autorización de residencia sin poder trabajar, se creaba una situación de dependencia económica y de absurda restricción de integración social y desarrollo de la propia personalidad, en la medida que el trabajo la proporciona; de otro lado, por primera vez se otorga carta de naturaleza a la análoga relación de afectividad respecto del matrimonio, con lo que se reconocen otras formas de convivencia muy extendidas en países de origen de muchos de nuestros inmigrantes que, pese a tener dilatadas convivencias de años e hijos en común, se encontraban con que se les negaba la posibilidad de reagrupación ante la ausencia de matrimonio. Otra cosa será como reglamentariamente se regula dicha materia, qué requisitos se exigen para acreditar la "análoga relación de afectividad", cuánto tiempo de convivencia conjunta, etc.

El aumento de las sanciones y multas para los responsables de la inmigración ilegal y la explotación laboral también es una medida correcta que se arbitra en

\footnotetext{
${ }^{26}$ Así se recoge en la renovación de la residencia de los menores, o en el artículo 31.7 para la renovación de la autorización de residencia: "se valorará especialmente el esfuerzo de integración del extranjero que aconseje su renovación, acreditado mediante un informe positivo de la Comunidad Autónoma que certifique la asistencia a las acciones formativas contempladas en el artículo 2 ter de esta ley".
} 
dos sentidos: de un lado se actualizan las cuantías económicas de las sanciones, lo que resultaba necesario por el incremento del coste de la vida desde la última reforma del año 2003, amén del efecto disuasorio que ello conlleva. Y de otro lado, se amplían también los supuestos de hecho tipificados y sancionables como simular una relación laboral, contraer matrimonio en fraude de ley, etc.

Sin embargo, consideramos que en el ámbito sancionador existe una excesiva casuística y ampliación de supuestos relacionados con las conductas de los inmigrantes, que lleva a una criminalización indeseada y discriminatoria de éstos. Penalizar ahora el consentimiento de la inscripción del empadronamiento cuando no sea real el domicilio supone un agravamiento que no se aplica a los españoles que alteran el domicilio para acceder a un centro educativo determinado, por ejemplo. También se incluye ahora como infracción el trabajar dentro de una provincia o actividad distinta a la recogida en la autorización de residencia y trabajo, lo que llevados de la actual situación de desempleo, acrecentada sobre todo entre la población extranjera, nos lleva de nuevo a castigar doblemente al extranjero: con el desempleo y con la restricción a encontrar un trabajo para su sustento fuera de los límites geográficos y de actividad que la Administración le impone.

Finalmente, se incorporan como control de legalidad diversos mecanismos de garantía. Así la exigencia de motivación respecto de la resolución de los visados de estancia, y alguna mayor flexibilidad en el régimen de las inadmisiones a trámite según la nueva Disposición Adicional Cuarta. Resultan muy positivos la regulación del acceso de las asociaciones humanitarias a los centros de internamiento administrativos y el mayor control judicial de los mismos mediante la creación de un "juzgado de vigilancia" de estos centros.

\section{Lagunas y discordancias}

La reforma ha sido, en general, cicatera con los derechos de los inmigrantes, que se ven recortados en numerosas ocasiones y no ha logrado elaborar una norma capaz de responder a una sociedad multiétnica, respetuosa con los derechos de las personas, sobre todo en lo que se refiere a ciudadanía. Entre los aspectos de la reforma que han suscitado mayores polémicas, destacan principalmente seis materias que comentamos a continuación.

La limitación al derecho de reagrupación familiar sólo a favor de los extranjeros residentes de larga duración respecto de sus ascendientes mayores de 65 años por razones "justificables" y aplicando criterios discrecionales evitando además las 
reagrupaciones en cadena, nos parece pernicioso para el derecho fundamental a vivir en familia y ello, pese al descenso notable de la concesión de autorizaciones de residencia a familiares reagrupados en 2008 respecto de los 128.161 concedidas en 2007. Estas nuevas exigencias no favorecen el marco familiar en que debe producirse la integración social de los extranjeros, además de contravenir el tenor de la Directiva 2003/86/CE del Consejo de 22 de septiembre de 2003, sobre el derecho a la reagrupación, cuyo artículo 4.2.a) establece que los Estados miembros podrán autorizar la entrada y residencia de los ascendientes del regrupante o de su cónyuge de conformidad con dicha Directiva siempre que cumplan las condiciones establecidas en ella. Una vez reconocida dicha posibilidad en el Derecho español, como señala el Dictamen a la Ley del Foro para la Integración Social de los Inmigrantes ${ }^{27}$, no cabe establecer el requisito de un periodo previo de residencia legal del reagrupante superior al que se pueda exigir para la reagrupación familiar con carácter general en la misma Directiva. En este sentido, el artículo 8 de ésta, único en el que se contempla el periodo previo de residencia legal necesario para la reagrupación familiar sin distinción de supuestos, establece que "los Estados miembros podrán requerir que el reagrupante haya residido legalmente en su territorio durante un periodo de tiempo que no podrá superar dos años, antes de reagrupar a los miembros de su familia con él". Por lo que, en conclusión, la regulación de la Ley de Extranjería exigiendo al reagrupante una residencia de larga duración es contraria a la normativa comunitaria.

También resulta criticable la posibilidad establecida con carácter general, frente al criterio tradicionalmente restrictivo, de la repatriación de los menores no acompañados, bajo el principio del superior interés del menor. Esto, en muchas ocasiones, realmente puede perjudicar al menor pues en sus países de origen o no existen garantías para el menor o éstas son insuficientes, tal y como han puesto de manifiesto las numerosas paralizaciones a las repatriaciones de menores por parte del Ministerio Fiscal, lo que ha provocado que en el año 2008 sólo se llevaran a cabo 10 repatriaciones de menores, aunque la voluntad del Ejecutivo era claramente otra ${ }^{28}$. Pero es que además, el nuevo artículo 35 de la LOEX no recoge el derecho de audiencia en todo caso de los menores de edad, sino que reconduce dicho derecho a quienes "tengan juicio suficiente". Nos preguntamos si quienes

\footnotetext{
${ }^{27}$ Dictamen aprobado por el Pleno de 28 de enero de 2009 del Foro para la Integración Social de los Inmigrantes, en www.mtin.es.

${ }^{28}$ El Gobierno de España cerró acuerdos de readmisión para menores extranjeros no acompañados con Rumania -BOE 16.08.2006-, con Senegal -BOCG 20.04.2007-, y con Marruecos -BOCG 14.09.2007-.
} 
han recorrido solos cientos o miles de kilómetros para llegar a nuestro territorio no tienen "juicio suficiente" a criterio de la Administración. El informe preceptivo realizado por el Consejo General del Poder Judicial sobre el Anteproyecto de Ley ya señalaba el respeto al principio del favor minoris recogido en la Carta Europea de los Derechos del Niño y en el artículo 3 de la Convención sobre los Derechos del Niño, y esa preferencia por la reagrupación familiar exige la conciliación con el respeto a un procedimiento específico para llevarlo a cabo, y requiere la mención expresa a la necesaria audiencia del menor en dicho procedimiento, que finalmente no se ha garantizado en todos los casos.

Nos parece excesiva e injustificada, por cuanto supone la privación de derechos fundamentales por una falta administrativa, la ampliación del tiempo máximo de estancia en los centros de internamiento de 40 a 60 días, lo que incluso va más allá de lo que se permite en casos de extradición penal por los tratados internacionales para personas delincuentes. No resulta ajena a dicha reforma la normativa comunitaria, cuya Directiva 2008/115/CEE del Parlamento Europeo y del Consejo de 16 de diciembre de 2008, contempla en su artículo 15.5 que cada Estado miembro fijará un periodo limitado de internamiento que no podrá superar los seis meses. España, sin tener obligación para ello, pero aprovechándose de ese margen establecido en la normativa europea, ha sido el primer país en trasponer a su legislación de extranjería esta Directiva conocida como la Directiva de la vergüenza.

Afortunadamente, finalmente se mejoró el texto inicial del artículo 62 del proyecto, que era mucho más criticable. Éste preveía que dicho cómputo de plazo pudiera ser suspendido por numerosas causas, tales como la tramitación y resolución de los procedimientos de asilo o de "habeas corpus", o además en caso de enfermedad del extranjero o por otras causas no imputables a la Administración que impidiesen - dificultasen la salida de España del extranjero. Lo que le hubiese llevado a un internamiento más prolongado y la consiguiente privación de libertad mucho más duradera, que no concuerda con el carácter restringido y excepcional que debe tener la privación de libertad con origen en una falta administrativa. Finalmente, tras una dura polémica, y la recomendación vertida en el Dictamen del Consejo General del Poder Judicial de que había que limitar la duración máxima de dicho internamiento, dicho inciso fue suprimido de la redacción final.

Respecto del derecho a la educación, como derecho fundamental, no se adopta la doctrina del Tribunal Constitucional ${ }^{29}$ que lo protege como derecho fundamental en

${ }^{29}$ STC 236/2007, Fundamento Jurídico $8^{\circ}$ 
las mismas condiciones que los españoles sin distinguir, como lo hace la reforma, entre la enseñanza obligatoria y las etapas educativas pos obligatorias, y la educación infantil que no es tampoco obligatoria antes de los 6 años. Efectivamente, el máximo intérprete de nuestra Constitución vino a señalar que el derecho a la educación constitucionalmente garantizado en el artículo 27.1 CE corresponde a "todos" independientemente de su condición de nacional o extranjero, e incluso de su situación legal en España, lo que interpretado de conformidad con la Declaración Universal de los Derechos Humanos y los Tratados y Acuerdos internacionales, se deduce que el contenido constitucionalmente garantizado de ese derecho en su dimensión prestacional, sigue diciendo el Alto Tribunal, no se limita a la enseñanza básica, sino que se extiende también a los niveles superiores, aunque en ellos no se imponga constitucionalmente la obligatoriedad y la gratuidad. De esta manera el derecho a la educación resultante del nuevo texto legal y el acceso a becas sigue discriminando a los extranjeros no residentes mayores de edad, obviando la vinculación entre educación e inclusión social.

En materia sancionadora, la lucha por el control de la inmigración irregular ha llevado también a la incorporación de nuevos supuestos sancionadores, que bien pueden ser entendidos como un paso más hacia la criminalización de las personas inmigrantes en situación irregular y su esfera sociofamiliar. En este sentido, hay también que destacar que el cumplimiento del principio de proporcionalidad en los procedimientos sancionadores, debe tener su plasmación tanto en las cuantías y grados de las sanciones, como en la elección de los procedimientos establecidos en la norma, preferente $u$ ordinario, para aplicarlas. Aspecto éste que sigue quedando, por consentimiento de la ley, en el margen de la práctica habitual de los agentes policiales que suelen optar, de forma habitual y casi automática, en muchos casos, por la aplicación del procedimiento preferente.

Un claro referente en lo que concierne a la filosofía de la reforma legislativa, a ese carácter cicatero en el reconocimiento de derechos denunciado, inspirado en la legislación italiana tendente a criminalizar el apoyo a las personas indocumentadas, se vislumbra con claridad con la propuesta contenida en el artículo 53.2.c) que generó un aluvión de protestas, y una campaña denominada "salvemos la hospitalidad", con manifiestos y recogida de firmas. Efectivamente, dicho precepto castigaba como falta muy grave con multa de hasta 30.000 euros, a quien promoviese la permanencia irregular en España de un extranjero, considerando por tal cuando el extranjero dependa económicamente del infractor y se prolongue la estancia autorizada más allá del plazo legalmente previsto. Se hubiera conseguido intimidar a los ciudadanos españoles o extranjeros con papeles para que denieguen toda forma de apoyo a la persona en situación irregular y ésta se quede sin 
ningún tipo de ayuda, materialmente desasistida y en precariedad absoluta. Con ello se privaba a los extranjeros de apoyo social solidario, y convertía en ilegal un principio-valor tan necesario estructuralmente en un estado como es la solidaridad. Se trataba de un precepto patético, que fue aprobado en el Anteproyecto de la Ley por el Consejo de Ministros, y que finalmente fue desestimado tras la advertencia señalada en el Dictamen del Consejo General del Poder Judicial ${ }^{30}$ y del Foro para la Integración Social de los Inmigrantes. Podría surgir la duda en el texto actual, no obstante, sobre la supuesta falta grave en que puede incurrir la persona que invita al extranjero que tras cumplir su estancia legal en nuestro país, decide quedarse en el mismo irregularmente, en aplicación de lo dispuesto en el artículo 53.2.c de la Ley de Extranjería que, en su reforma, sigue penalizando al que promueva la permanencia irregular de un extranjero, aunque nos parece que dicho precepto tiene más un carácter psicológico y disuasorio que de aplicación real efectiva, salvo que se evidencien desde un primer momento pruebas firmes sobre el supuesto fraude de ley concertado desde el principio entre invitador e invitado, para utilizar la invitación como cauce formal de entrada al país sin intención alguna de abandonarlo al terminar el mismo, aunque conociendo la práctica del foro nos parece que este precepto será de una aplicación muy restrictiva.

Otro ejemplo de esa regulación cicatera y miope con los derechos de los extranjeros, lo encontramos en la regulación de los derechos en materia de vivienda recogidos en el artículo 13 de la Ley, derechos a los sistemas públicos de ayudas en materia de vivienda reservados a los extranjeros residentes. ¿ंTendrá un extranjero indocumentado derecho a una vivienda pública cuando se den criterios objetivos de emergencia social? En todo caso, dice la Ley, sólo los extranjeros residentes de larga duración tienen derecho a dichas ayudas en las mismas condiciones que los españoles. No acertamos a entender por qué se limita a los extranjeros residentes de larga duración dichas ayudas en una materia tan sensible como la vivienda, en la que los extranjeros acceden al mercado inmobiliario con especiales dificultades de toda índole que, precisamente, el legislador, no quiere corregir sino perpetuar. Ese carácter restrictivo de limitar a la población extranjera las prestaciones y ayudas sociales, viene marcando una línea de actuación que no es novedosa, y ya en la regulación de la renta básica de emancipación ${ }^{31}$ se exige la residencia

\footnotetext{
${ }^{30}$ Apartado H del Dictamen: "En relación con esta previsión, y con el fin de que no pueda incluirse como conducta infractora la actividad puramente solidaria de aquellas entidades que, sin animo de lucro, dedican su actividad a la atención social de los inmigrantes, debería examinarse la posibilidad de excluir de este tipo a esos actos de hospitalidad realizados con carácter solidario y sin ánimo de lucro".

${ }^{31}$ Recogida en el Real Decreto 1472/2007, de 2 de noviembre.
} 
legal y permanente de 5 años para acceder a las ayudas destinadas al alquiler de vivienda.

Como una concesión a las comunidades autónomas puede interpretarse la introducción por enmienda parlamentaria del apartado 2 del artículo 35 sobre menores no acompañados, que no se incluía en el anteproyecto de Ley que aprobó el Consejo de Ministros. El mismo llama la atención por cuanto establece la capacidad de las Comunidades Autónomas de establecer acuerdos con los países de origen dirigidos a procurar que la atención e integración social de los menores se realice en su entorno de procedencia. Dos anomalías se nos plantean sobre dicho precepto. La primera que se contradice con el párrafo primero de dicho artículo, donde corresponde al Gobierno promover el establecimiento de Acuerdos de colaboración con los países de origen que contemplen, integradamente, la prevención de la inmigración irregular, la protección y el retorno de los menores no acompañados, siendo las Comunidades Autónomas informadas de tales acuerdos. Con lo que, tanto Gobierno como Comunidades Autónomas, están facultadas para lo mismo. No parece lo adecuado por la duplicidad y confusión que puede llegar a crear, además de porque no están al mismo nivel para negociar acuerdos con un país extranjero el Gobierno de la Nación que el de la Comunidad Autónoma.

La segunda discordancia sobre este artículo 35.2 se refiere a la capacidad competencial de las Comunidades Autónomas de establecer acuerdos con terceros países. Lo que pudiera interpretarse en contradicción con las funciones exclusivas del Estado que le confiere el artículo 149.1 de la CE en materia de relaciones exteriores. Sólo en ese proceso de centrifugación del Estado se puede interpretar dicho precepto, de dudosa legalidad, al ser incluido en el trámite parlamentario con ausencia de los dictámenes previos preceptivos. A ello se une el caos que supondría la aplicación práctica de dicho precepto llevado a sus extremos: por ejemplo, el Reino de Marruecos podría llegar a tener 5 ó 7 acuerdos con regímenes diferentes sobre la misma materia con diversas comunidades autónomas españolas, quedando otras sin acuerdo alguno.

La penúltima entrega en este capítulo de despropósitos en materia de extranjería, posterior a la publicación de la nueva Ley, pero que nos ilustra sobre su filosofía y mecanismos de aplicación, lo encontramos en la Circular 1/2010 de la Dirección General de la Policía ${ }^{32}$ que recomienda las detenciones "preventivas" de

32 Circular número 1/2010, de 25 de enero, de la Comisaría General de Extranjería de la Dirección General de la Policía y de la Guardia Civil, del Ministerio del Interior, de Instrucciones sobre determinadas actuaciones policiales derivadas de la nueva Ley 2/2009 de 11 diciembre, que modifica la LO 
extranjeros para su documentación contra lo dispuesto en el artículo 20.2 de la Ley de Seguridad Ciudadana, que según la Circular podrán ser transformadas en detenciones "cautelares" para aperturar el procedimiento sancionador preferente de expulsión en su caso, lo que ha llevado a las airadas y justificadas protestas de los sindicatos policiales -SUP y CEP- y del Consejo General de la Abogacía Española dado que, no solo es contraria a los derechos ciudadanos tutelados por el Ordenamiento, sino que sólo pretende sembrar el miedo entre éstos e inflar las estadísticas policiales de detenciones que acrediten una eficacia que, en cualquier caso, debe dirigirse contra los criminales y no contra quienes quieren sobrevivir y mejorar honestamente sus condiciones de vida.

\section{La cuestión del empadronamiento}

Durante el mes de enero del presente año, hemos asistido a una intensa polémica sobre la cuestión del empadronamiento de inmigrantes sin documentación en algunos municipios españoles, entre los que destacó el Ayuntamiento de Vic, cuestión que no es nueva y ya motivó actuaciones de diversas Defensorías, como la del Ararteko vasco ${ }^{33}$. La reforma de la Ley de Extranjería también aborda este tema al que, por su consideración mediática y su particular alcance, dada la movilidad de la población extranjera y la incidencia del empadronamiento sobre sus derechos, hemos querido destinar un epígrafe diferenciado.

\section{I. El empadronamiento en la reforma legal}

Empadronamiento y extranjería han estado relacionados desde la Ley de Extranjería 4/2000 que reconocía al empadronamiento como generador de determinados derechos, hasta el punto de que son cuatro las categorías jurídicas de extranjeros en nuestro país: comunitarios y extracomunitarios residentes legales, indocumentados empadronados, e indocumentados. Después la Ley 14/2003 amplió la regulación en este ámbito obligando a la renovación del empadronamiento cada dos años para los extranjeros sin autorización permanente, lo que viene siendo un dislate

4/2000 de 11 de enero, de Extranjería y recordatorio de otras actuaciones. Ha sido aclarada por la Circular de 9 de febrero de 2010.

${ }^{33}$ Véase hitp://blogs.ararteko.net/dil/2010/01/20/dificultade-de-las-personas-inmigrantes-parainscribirse-en-padrones-municipales/ 
porque es discriminatorio respecto de los nacionales, resulta lejano a la cultura administrativa de la inmensa mayoría de los extranjeros que, además, no conocen dicha obligación legal, que es inoperativo por la movilidad geográfica de éstos y que, en definitiva, está siendo un control más de extensa inaplicación.

Ahora, han sido dos los cambios introducidos en esta materia: uno en la incorporación de los extranjeros al padrón, y el otro en materia sancionadora. Efectivamente, el artículo 6.3 de la LOEX, dedicado a la participación pública, ha cambiado el texto anterior que incluía la incorporación al padrón y su actualización por los Ayuntamientos de los extranjeros que residieran en el municipio, por aquéllos que tengan su domicilio habitual en él. Esto puede llevar a situaciones de vacío legal e injusticia social, porque el término "habitualidad" es un concepto jurídico indeterminado: ¿qquiere decir una semana o dos meses o tal vez seis meses?, $\dot{2}^{\text {no }}$ podrá un extranjero que cambie de localidad inscribirse en el padrón municipal nuevo a su llegada; entonces cómo ejercitará sus derechos? El que la determinación de la "habitualidad" quede a la discreción de un reglamento de desarrollo o una normativa de inferior rango, deja el ejercicio de derechos sociales y fundamentales de muchas personas a la discrecionalidad de la Administración, provocando ínterin además toda suerte de inseguridad jurídica.

La otra reforma del empadronamiento la encontramos en el artículo 53 LOEX que recoge ahora un ampliado catálogo de infracciones graves, en el que castiga la falsedad en la declaración de los datos obligatorios para cumplimentar el alta en el padrón municipal, exigiendo la delación de cualquier autoridad que tuviese conocimiento de ello; por otro lado, castiga a quien consienta la inscripción de un extranjero en el padrón por parte del titular de una vivienda habilitado para tal fín, siempre que dicha vivienda no constituya el domicilio real del extranjero. Aunque pudiésemos comprender dicha reforma por la intención de luchar contra el llamado "tráfico de empadronamientos" y contra los "pisos patera" donde permanecen empadronados numerosos extranjeros, debemos ponderar, sin embargo, los argumentos negativos para dicha reforma que recoge el Dictamen del Foro para la Integración Social de los Inmigrantes. Éste propugna directamente la supresión de dicho precepto, por cuanto no se debe convertir la Ley de extranjería en una ley sancionadora especial en donde vayan incluidas todas las infracciones que tengan que ver con elemento extranjero, de tal suerte que cualquier infracción y sanción por falsedad en la declaración de los datos del padrón debería ser tratada en su normativa específica con las consecuencias en la misma previstas, pues lo contrario supone llevar la naturaleza de relación de sujeción especial de los extranjeros a límites indeseados. Tesis que compartimos como más acertada, aunque no ha tenido ningún éxito en la reforma legal. 


\subsection{La obligación del empadronamiento}

En el artículo 15 de la Ley 7/1985 de Bases de Régimen Local (LBRL) se recoge que la condición de vecino se adquiere en el mismo momento de su inscripción en el padrón, y obliga a toda persona que viva en España a inscribirse en el padrón del municipio en el que resida habitualmente (entendiendo por éste aquél en el que habita durante más tiempo al año, en el caso de que la persona viva en varios municipios).

De tal forma, que sus efectos son fundamentales para la obtención de la residencia por arraigo de las personas extranjeras indocumentadas que deben acreditar la estancia de 3 años en nuestro país, o para la obtención de la documentación en los procesos de regularización que exigen un determinado tiempo de estancia. No en vano, el artículo 16 de la LBRL indica que el padrón municipal es el registro administrativo donde constan los vecinos de un municipio. Sus datos constituyen prueba de la residencia en el municipio y del domicilio habitual en el mismo, teniendo las certificaciones que se expidan de dichos datos carácter de documento público y fehaciente para todos los efectos administrativos. Si bien el artículo 18.2 de la LRBRL distingue expresamente que la inscripción de los extranjeros en el padrón municipal no constituye prueba de su residencia legal en España.

Obligación que se corresponde con la señalada en el artículo 6 de la LOEX que recoge la obligación de los Ayuntamientos de incorporar al padrón a los extranjeros que tengan su domicilio habitual en el municipio.

Como datos obligatorios para la inscripción en el padrón se exige ${ }^{34}$ la anotación del nombre y apellidos, sexo, domicilio habitual, nacionalidad, lugar y fecha de nacimiento, certificados de estudios o académicos que se posean, número del documento de identidad (o en el caso de los extranjeros el número de la tarjeta de residencia en vigor expedida por las autoridades españolas o, en su defecto, el número del documento de identidad o del pasaporte expedido por las autoridades de su país de procedencia). En consecuencia, ninguna norma exige al extranjero probar que su residencia en España sea regular, no siendo competencia de los ayuntamientos la policía de extranjeros.

\footnotetext{
${ }^{34}$ Artículo 16.2 LBRL
} 
A igual conclusión llega el Reglamento de Población y Demarcación Territorial de las Entidades Locales ${ }^{35}$, que refiere o vincula la obligación de inscribirse en el padrón al hecho o dato, puramente fáctico, de vivir en territorio español, no exigiéndose en ningún caso el dato jurídico de la residencia legal. No puede argumentarse tampoco la necesidad de visado en el pasaporte, por cuanto éste no es preceptivo para ciudadanos de numerosos países como ocurre a los ciudadanos comunitarios y otros recogidos en convenios internacionales por nuestro país, ni exigido en la legislación española para el empadronamiento.

Criterio de obligatoriedad que, como intentó el Ayuntamiento de Vic, no queda desvirtuado por la exigencia de visado o estancia legal en nuestro país exigido por la propia LOEX, dado que el padrón tiene por misión constatar el hecho de la residencia, facultando a los Ayuntamientos a cursar altas y bajas de oficio para que la realidad se corresponda con dicho padrón ${ }^{36}$. Por ello el reciente informe de la Abogacía del Estado concluyó que la inscripción de los extranjeros en el padrón municipal procede con independencia de que los mismos tengan o no residencia legal en territorio español, por lo que no resulta procedente denegar la inscripción so pretexto de que el ciudadano extranjero no reside legalmente en España ${ }^{37}$. En consecuencia, la actuación municipal denegatoria de la inscripción en el padrón de cualquier Ayuntamiento, a sabiendas de la injusticia de su resolución, nos llevaría a incurrir en una conducta tipificada y penada en el artículo 404 del Código Penal como prevaricación administrativa.

\subsection{Una contradicción más del sistema normativo}

Toda esta polémica de algunos Ayuntamientos españoles tiene algún sentido. Algunos pudieran pensar que se trata de un instrumento más para desestabilizar al contrario dentro de los pulsos políticos entre partidos. Otros no aciertan a com-

\footnotetext{
${ }_{35}$ Aprobado por Real Decreto 1690/1986, de 11 de julio, que reproduce en sus artículos 53 y 54 lo indicado en la Ley de Bases de Régimen Local.

${ }^{36}$ En tal sentido, es ilustrativa la Resolución de 4 de julio de 1997, conjunta de la Presidenta del Instituto Nacional de Estadística y del Director General de Cooperación Territorial que señala: "el Ayuntamiento ni interviene en la concesión de los permisos de residencia ni es competente para controlarlos. Su obligación es reflejar en un registro, el Padrón, el domicilio y las circunstancias de todas las personas que habitan en su término municipal".

${ }^{37}$ Conclusión primera, del Informe del Abogado General del Estado Joaquín de Fuentes Bardají, de 20 de enero de 2010, remitido al Ayuntamiento de Vic.
} 
prender cómo un municipio que recibe más aportaciones presupuestarias cuantos más habitantes tenga, puede negarse a empadronar a personas por las que va a recibir del Estado y la Comunidad Autónoma determinadas aportaciones económicas. Pero es que en el fondo, además de la articulación de la convivencia desde la diversidad y la pluralidad que esta realidad impone, existe una contradicción en nuestro Ordenamiento.

Efectivamente, los extranjeros indocumentados, a la vez que pueden ser detenidos y expulsados por su situación administrativa de nuestro país, donde no pueden trabajar ni residir legalmente según la Ley de Extranjería, gozan de determinados derechos si se encuentran empadronados en nuestro Estado, como por ejemplo el derecho a la atención de los servicios sociales comunitarios, el derecho a la educación o al disfrute de la asistencia sanitaria como recoge el artículo 12 LOEX ${ }^{38}$. Esa carga asistencial, en la mayoría de los casos tienen que afrontarla municipios que, en tiempos de crisis, no tienen los recursos económicos suficientes, por lo que vuelve de nuevo el criterio del balance economicista, y entienden que es más lo que el extranjero recibe en aportaciones y prestaciones, que con lo que contribuye, sobre todo si se encuentra en desempleo. Empadronamiento que, como hemos indicado más arriba, es relevante para el extranjero, porque hace prueba de la estancia en nuestro país: llegado a los tres años, cual premio a la perseverancia, puede legitimar la obtención de un permiso de residencia o el cumplimiento de los requisitos para una regularización administrativa.

El colmo de dicha contradicción lo encontramos en la Disposición Adicional Séptima de la LOEX ${ }^{39}$ que faculta a la Dirección General de la Policía a obtener del padrón los datos sobre todos los inmigrantes, incluyendo los indocumentados sin permiso, su nombre y domicilio para localizarlos en cualquier momento y proceder al procedimiento de expulsión. Con lo que el extranjero tiene que empadronarse para poder ir al médico, y podrán detenerle y expulsarle si se empadrona. Es además de una contradicción, una perversión, y por eso muchos ayuntamientos se niegan ahora a cumplir con este apartado de la ley y niegan esa información a los Cuerpos y Fuerzas de Seguridad del Estado.

\footnotetext{
${ }^{38}$ Artículo 12.1 LOEX: "Los extranjeros que se encuentren en España, inscritos en el padrón del municipio en el que tengan su domicilio habitual, tienen derecho a la asistencia sanitaria en las mismas condiciones que los españoles".

${ }^{39}$ Introducida en la reforma de la LOEX por la LO 14/2003, recurrida por inconstitucionalidad por el Parlamento Vasco y actualmente pendiente de sentencia.
} 


\section{Consideraciones finales: bases de una futura regulación legal y conclusiones}

Debemos de virar el rumbo de nuestras políticas de inmigración. El futuro pasa necesariamente por cuatro aspectos interrelacionados que deben centrar nuestros esfuerzos: la gestión compartida de los flujos migratorios y el codesarrollo desde la globalidad con los países de origen emisores, una pedagogía social sobre la inclusión y la interculturalidad, una legislación basada en la ciudadanía, y finalmente un pacto social y de Estado que abarque a los partidos políticos, organizaciones sociales y los diversos niveles de la Administración. Si el Gobierno español ya señaló, por su parte, en el año 2004 que sus cuatro pilares de política integral en inmigración serían la lucha contra la inmigración ilegal, dar respuesta a las necesidades del mercado de trabajo, la cooperación al desarrollo y el plan estratégico de ciudadanía e integración de 2007-2010, su desarrollo y aplicación ha resultado desigual en función de la mala coyuntura económica, de una visión restrictiva y sobrepasada en la regulación de la inmigración y en una escasa pedagogía social, por lo que sería necesaria una revisión realista y generosa de dichos principios.

En primer lugar no se puede abordar la inmigración desde puertas adentro, o aplicando solamente transposiciones de normativa comunitarias basadas en la Europa-Fortaleza y en el sistema de control de fronteras Frontex. Si queremos soluciones serias hay que levantar la vista y no dejar de lado a los países emisores, desarrollando políticas de gestión compartida de flujos y codesarrollo reales, pactadas desde las necesidades de los Estados menos favorecidos, que no se basen en comprar voluntades ni en ir regalando patrulleras a quienes, a la postre, ni siguiera tienen preparación para utilizarlas ni voluntad de impedir a su población que salga de sus fronteras en busca de un porvenir mínimamente digno. La Unión Europea debe ser protagonista en focalizar planes de desarrollo educativos, productivos e industriales en todo el norte de Africa y en otras zonas, siendo nuestro país locomotora de dicha promoción del codesarrollo. No puede ser que sigamos explotando y diezmando recursos ajenos, dificultando sus exportaciones, determinando qué mano de obra nos interesa y respecto de qué países, imponiendo acuerdos de repatriación a gobiernos corruptos, en una visión sesgada y utilitarista del ser humano. Debemos invocar, tal vez, otros modelos de integración como los desarrollados en países escandinavos o en Canadá que, con sus diferencias, nos indican que existen otros espejos en los que mirarse. Podemos demandar, por ejemplo, la aplicación de Convenios internacionales emanados en el seno de la Asamblea General de Naciones Unidas como el aprobado por la Resolución 45/158 de 18 de diciembre de 
1990, sobre las condiciones y derechos de los trabajadores inmigrantes y sus familiares que, pese a estar en vigor, vergonzosamente no ha sido ratificado aún por ningún estado europeo.

La segunda apuesta, es una pedagogía social sobre la inclusión y la interculturalidad. Frente al debate exacerbado de las razas y las identidades, de las religiones contrapuestas y los nacionalismos excluyentes, de los contratos de integración y los guetos, se impone una pedagogía sobre la convivencia intercultural, multiétnica, superando modelos fracasados como el "apartheid" de los trabajadores invitados en Alemania primero, y después el asimilacionismo francés o el multiculturalismo británico. Y más en tiempos de crisis donde el extranjero se convierte en diana oportunista e interesada de todos los males, en "competidor" de todos los servicios y prestaciones. Necesitamos un plan de pedagogía sobre interculturalidad, pero no sólo con los inmigrantes, sino con los sindicatos y empresarios, con la universidad y los medios de comunicación, con los colectivos ciudadanos y la enseñanza que nos lleve a una nueva mentalidad, más cercana a otros países cosmopolitas donde la integración es plena.

El tercer gran pilar es una legislación integradora, inclusiva, donde los extranjeros no tengan un régimen especial y paralelo de derechos y obligaciones ${ }^{40}$. En una sociedad global, con 5.600.000 extranjeros en nuestro país que siguen aumentando, con necesidad futura de importar 20 millones de extranjeros en Europa para mantener el crecimiento demográfico y numerosos sectores de actividad, es una locura hacerlo desde la exclusión. La alternativa es la ciudadanía plena de quienes forman parte de una misma comunidad política, con los mismos derechos y obligaciones a partir de un determinado periodo de residencia razonable. No puede ser que los extranjeros sean nuestros vecinos, paguen sus impuestos pero tengan restringidos sus derechos políticos, voten en las municipales según su país de origen y criterios de reciprocidad, y en el resto de comicios no se les permita, como si no fuesen destinatarios de las decisiones que ese poder político pudiese determinar. Es un déficit democrático, que se traduce escalonadamente en una discriminación sobre derechos sociales, económicos, educativos, etc. Pero no se puede dar este paso, sin esa pedagogía social de la interculturalidad con carácter previo. No puede ser que unos legislen sobre los derechos de los otros como antaño ocurrió con las mujeres, no cabe privar en el siglo XXI a los extranjeros que viven en nuestra comunidad del derecho de reunión, manifestación, asociación

${ }^{40} \mathrm{El}$ artículo $14 \mathrm{CE}$, paradigma de la igualdad, no dice que todas las personas somos iguales ante la ley, sino que "los españoles son iguales ante la Ley", justificando una legislación para españoles y otra para extranjeros. 
- huelga como ha ocurrido durante siete años hasta las sentencias del Tribunal Constitucional. Si no queremos seguir los pasos de la Francia de Le Pen, de la Austria ultraderechista o de la Italia de La Liga Norte de Bossi, urge cambiar un modelo que se retroalimenta creando más xenofobia y exclusión. Para ello, se proponen dos modificaciones en nuestro texto constitucional: que la igualdad ante la ley se predique en el artículo 14 de toda persona, no sólo de "los españoles" como hasta ahora; y que el artículo 13 no exija el criterio de la reciprocidad para la participación política plena de los ciudadanos extranjeros que gocen de una residencia permanente en nuestro país.

El cuarto pilar, sin el que no se puede llevar adelante lo anterior, es un gran pacto social y de Estado, donde saquemos la extranjería de las confrontaciones electorales y los réditos de partido. Un pacto en horizontal y en vertical, hacia todos los estamentos sociales, y hacia todas las administraciones públicas, que lejos de los vaivenes actuales y la ausencia de modelos definidos, consagre una orientación estable, una estrategia común en el corto, medio y largo plazo que cierre filas en torno a la interculturalidad y la ciudadanía, que ponga en el centro la dignidad de la persona humana y los derechos que le son inalienables. Ese pacto hay que dirigirlo desde arriba, pero cimentarlo desde abajo, desde la sociedad civil, para que sea una demanda incontestable que todos asuman como propia.

Por tanto, podemos concluir que la nueva ley de extranjería del gobierno de turno, disfrazada como reforma, supone un avance en un modelo desfasado $y$, por tanto, resulta totalmente insuficiente. El portavoz del PNV en el debate parlamentario de la Ley, el Sr. Olabarría Muñoz citaba en el atril del Congreso ${ }^{41}$ el ensayo de Ortega "Mirabeau o el político", diciendo que las leyes pueden ser buenas o malas, pero siempre insuficientes, porque así se mantiene viva la reivindicación y consolida la absoluta imprescindibilidad de los políticos a la hora de solucionar dichas reivindicaciones. Esperemos que el sentido común, que no siempre es el más común de los sentidos, y la reciente entrada en vigor del Tratado de Lisboa, con su Carta de Derechos Fundamentales y Convenio de Derechos Humanos, abran una vía de reflexión que vayan más allá de la retórica habitual y nos ayuden a cohesionar una sociedad que nunca más será aquella que fue.

41 Diario de Sesiones del Congreso de los Diputados, de 26 de noviembre de 2009, pág. 17. 


\section{Bibliografía}

ADAM MUÑ̃Z, M ${ }^{a}$. D. (2005) "El estatuto jurídico del extranjero en el sistema español: una perspectiva histórica", publicado en Nacionalidad, Extranjería y Ciudadanía en la Unión Europea (coord. Adam Muñoz M. D. y BlázQuez Rodríguez, I.), Madrid, Colex, pp. 36 y ss.

Aguado I Cudolá, V. (2004) "Las causas de inadmisibilidad en los procedimientos administrativos en materia de extranjería: los problemas de inconstitucionalidad de la disposición adicional cuarta de la Ley orgánica 14/2003, de 20 de noviembre": Revista de Derecho Migratorio y Extranjería, n 5, p. 134.

Álvarez Rodríguez, A. (2003) "La entrada en vigor de la convención internacional sobre la protección de todos los trabajadores migratorios y sus familiares, de 18 de diciembre de 1990": Revista de Derecho Migratorio y Extranjería, n², p. 11.

Aparicio Gómez, R. (2002) "La inmigración en el siglo XXI: las novedades de las actuales migraciones": La inmigración en España: contextos y alternativas (coord. García Castaño, F. J.), Actas del III Congreso Nacional de Inmigración, volumen II, Granada, pp. 31-40.

DE LuCAS MARTín, J. (2002) "Sobre el papel de los derechos humanos en las políticas de inmigración. La necesidad de otra mirada sobre la inmigración, en tiempos de crisis": La inmigración en España: contextos y alternativas (coord. GARCíA CASTAÑo, F. J.), Actas del III Congreso Nacional de Inmigración, volumen II, Granada, p. 52.

García-Calabrés CoBo, F. (2003) La extranjera, estudio de la inmigración femenina en España, Córdoba, Consejería de Gobernación - Junta de Andalucía, p. 33.

García-Calabrés Cobo, F. (2001) "Políticas de inmigración en Andalucía" en Diversidad Cultural, identidad y ciudadanía, INET, pp. 121-131.

Pérez Milla, J. (2004) "De un status laboral mínimo para situaciones de migración irregular": Revista de Derecho Migratorio y Extranjería, n 5, pp. 9-15.

Pérez Vera, E. (1984) "Comentarios a las Leyes Políticas" (coord. Alzaga Villaamil, O.), tomo II, Revista de Derecho Privado, Madrid, pp. 233-235.

Ruiz del CASTILLO, M. M. (2003) "Marco legal de la Inmigración Europea": Revista Derecho Social n²1, Bomarzo, pp. 29-48. 
SagarRA TRIAS, E. (2002) "Un nuevo status de extranjero en España: El inmigrante, irregular, empadronado, residente, trabajando y con orden de expulsión", Revista de Derecho Migratorio y Extranjería, n 1, pp. 89-98

SAGARRA TRIAS, E. (2002) La legislación sobre extranjería e inmigración: una lectura de los derechos fundamentales y las libertades públicas de los extranjeros en España, Universidad de Barcelona.

SARTORI, G. (2001) La sociedad multiétnica. Pluralismo, multiculturalismo y extranjeros, Madrid, Taurus. 